\title{
Value of routine chest radiography in the diagnostic work-up of ill returned travelers
}

This article was published in the following Dove Press journal:

International Journal of General Medicine

4 December 2012

Number of times this article has been viewed

\section{David Severs' \\ Carla Moolenaar ${ }^{2}$ \\ Perry JJ van Genderen ${ }^{1,3}$ \\ 'Institute for Tropical Diseases, Rotterdam, The Netherlands; ${ }^{2}$ Department of Radiology, Harbor Hospital, Rotterdam, The Netherlands; \\ ${ }^{3}$ Travel Clinic, Harbor Hospital, Rotterdam, The Netherlands}

Correspondence: Perry JJ van Genderen Department of Internal Medicine, Institute for Tropical Diseases, Harbor Hospital, Haringvliet 72, 30I I TG Rotterdam, The Netherlands Tel +3I 104043305

Fax +3| 104 |2| 645

Email p.van.genderen@havenziekenhuis.nl
Background: Respiratory tract infections frequently occur in ill returned travelers, a minority of whom present with pneumonia. The most accurate and cost-effective diagnostic work-up remains an area of uncertainty. In this retrospective cohort study, the utility of routine chest radiography was evaluated.

Methods: This study was performed at the Institute for Tropical Diseases in Rotterdam and included all returned travelers in the period between 2007 and 2009 that were ill with symptoms lasting less than 1 month and had chest radiography on admission. Travelers' demographic (including travel history), clinical, and laboratory data were collected on admission and evaluated for their diagnostic power to predict radiographic evidence of a pulmonary infiltrate.

Results: Fifty-three (7\%) of 750 ill returned travelers had radiographic evidence of a pulmonary infiltrate. Presentation with cough (odds ratio [OR] 2.80, 95\% confidence interval [CI] 1.46-5.38), or elevated C-reactive protein values (OR 1.13, 95\% CI 1.09-1.17), and white blood cell count (OR 1.08, 95\% CI 1.05-1.17) strongly correlated with the presence of a pulmonary infiltrate. Recursive partitioning analysis identified a subset of 384 patients presenting with both cough and fever, or C-reactive protein values in excess of $23 \mathrm{mg} / \mathrm{L}$ that would optimally benefit from chest radiography.

Conclusion: The results of this study indicate that a more judicious use of chest radiography in the routine work-up of ill returned travelers is warranted.

Keywords: chest radiography, chest X-ray, travelers, pneumonia, routine, lower respiratory tract infection

\section{Introduction}

It is estimated that over 50 million people from industrialized countries travel to developing countries annually, and as many as $22 \%-64 \%$ of those travelers experience adverse health events related to their trip. Importantly, $8 \%$ of them are ill enough to seek medical advice. ${ }^{1-3}$ Respiratory tract infections occur in $10 \%-30 \%$ of those who become ill, ${ }^{1,4-6}$ a small minority of whom present with pneumonia. ${ }^{7}$ At the Institute for Tropical Diseases in Rotterdam, The Netherlands, ill returned travelers are evaluated following a standardized diagnostic protocol, which includes chest and sinus radiography. In this retrospective cohort study, the utility of routine chest radiography in the diagnostic work-up of ill returned travelers was evaluated. Analyses were done in the same cohort in whom the use of routine sinus radiography was evaluated. ${ }^{8}$

\section{Methods}

The Institute for Tropical diseases, a unit of the 161-bed Harbor Hospital located in Rotterdam, The Netherlands, serves as a national referral center for tropical diseases. 
All ill returned travelers presenting with acute symptoms (defined as lasting less than 1 month) who had chest radiography on presentation were included in this retrospective cohort study. For each traveler, demographic (including travel history), clinical, and laboratory data were collected, as well as chest radiography findings. After database entry, research data could not be traced back to individual patients. Chest radiography was performed in two directions: the posterior anterior view and the lateral view.

\section{Statistical analysis}

All values are presented as median (range). Comparison between groups was made with the nonparametric MannWhitney $U$ test. Contingency tables were analyzed with Fisher's exact test. Presentations with fever, cough, a feeling of malaise, symptoms of a common cold, and the inflammation parameters (C-reactive protein [CRP], erythrocyte sedimentation rate [ESR], and white blood cell [WBC] count) were evaluated in univariate and multivariate (forward stepwise) binary logistic regression. Due to their large ranges in comparison with WBC count, we transformed the variables ESR by dividing the values by three, and CRP by dividing the values by ten, respectively, for the logistic regression analyses. Odds ratios (OR) are given as the mean (95\% confidence interval $[\mathrm{CI}])$. Finally, a predictive algorithm to distinguish between patients at a high or lower risk for pulmonary infiltrate was constructed using recursive partitioning analysis, with the same variables used in the logistic regression analysis.

Recursive partitioning analysis belongs to a family of machine learning nonparametric techniques and can be used to explore relationships between predictive variables and outcomes in complex data. Classification and regression tree (CRT) analysis, which was the routine implemented in this study, aims to identify cohorts in populations that are as homogenous as possible with regard to the dependent variable. On each recursion, CRT seeks the variable and, if continuous, its cut-off value, that optimally identifies discrete subgroups until a stopping criterion, such as a minimum improvement in homogeneity or a minimum subgroup size of less than a predefined number (50 in this study), is reached. ${ }^{9}$ In our analysis, unequal misclassification costs were specified, so that misclassification as "no pulmonary infiltrate" was associated with a three times higher cost. Results are presented as a decision tree, which is intuitive and resembles clinical practice of diagnostic decisions. Statistical analyses were performed using the Statistical Package for the Social Sciences (SPSS) statistics software for Windows, version 20 (IBM Corporation, Armonk, NY).

\section{Results}

A total of 1024 patients who visited the Institute for Tropical Diseases from January 1, 2007 to December 31, 2009, were screened to identify those eligible for inclusion. Overall, 750 patients fulfilled the inclusion criteria, while 259 patients were excluded from analysis for not having a recent travel history. An additional 15 patients were excluded because of incomplete data. General patient characteristics are shown in Table 1. The median age was 39 years, ranging from 11 to 75 years. More males than females were included in our study, in an approximate 4:3 ratio. Moreover, 53 patients (7\%) had chest radiograph findings compatible with pulmonary infiltrate. No significant differences in age, gender, travel destination, and travel duration were seen between ill returned travelers with radiographic abnormalities and those without.

Fever and cough were found to be present more frequently in travelers with radiographic findings that were compatible with pulmonary infiltrate, while the presence of "common cold" and malaise was evenly distributed between the groups. Median ESR, CRP, and WBC count values were significantly higher in travelers with radiographic abnormalities than in those without, with median CRP values of $150 \mathrm{mg} / \mathrm{L}$ and $15 \mathrm{mg} / \mathrm{L}$ in the respective groups. Adjusted in multivariate logistic regression (the results of which are presented in Table 2), cough (OR $2.80[1.46-5.38, P=0.002])$, CRP (OR 1.13 [1.09-1.17, $P<0.001]$ ), and WBC count (OR 1.08 $[1.05-1.17, P=0.038]$ ) had significantly predictive value for the presence of a pulmonary infiltrate. Of note, malaise was found to correlate negatively with such radiographic abnormalities, while the presence of fever, common cold, and ESR levels were not significantly predictive.

To approximate efficient clinical practice where results of laboratory tests become available only at a later moment, and a decision on whether or not to order chest radiography is made at the earliest possible point in time, CRT analysis was first performed using the variables known at an early stage (ie, the presence of fever, cough, symptoms of malaise, and the "common cold"). The generated decision tree is shown in Figure 1. The presence or absence of fever was found to most accurately dissect the whole cohort into segments of greater homogeneity, where in the high-risk segment, $37(10 \%)$ of 370 patients presenting with fever had pulmonary infiltrates. In the remaining lower-risk segment, 16 of 380 patients (4.2\%) had pulmonary infiltrates. Using the presence of cough, both segments could be split into terminal segments, where the presence of both cough and fever resulted in the highest likelihood of finding a pulmonary infiltrate. Patients in the remaining three terminal segments were less likely to 
Table I General characteristics of patients

\begin{tabular}{|c|c|c|c|c|}
\hline & $\begin{array}{l}\text { Total } \\
n=750\end{array}$ & $\begin{array}{l}\text { Pulmonary infiltrate } \\
n=38\end{array}$ & $\begin{array}{l}\text { Normal chest radiography } \\
n=7 / 2\end{array}$ & $P$-value \\
\hline \multicolumn{5}{|l|}{ Sex } \\
\hline Male & 447 & 34 & 413 & ns \\
\hline Female & 303 & 19 & 284 & ns \\
\hline Age (years) & $40(11-75)$ & $44(2 \mid-70)$ & $39(11-75)$ & ns \\
\hline \multicolumn{5}{|l|}{ Travel destination } \\
\hline Europe & 10 & 0 & 10 & ns \\
\hline North America & 14 & I & 13 & ns \\
\hline South America & 122 & 9 & 113 & ns \\
\hline Africa & 359 & 20 & 339 & ns \\
\hline Asia & 265 & 24 & 241 & ns \\
\hline Oceania & 8 & 1 & 7 & ns \\
\hline Duration of travel (days) & $21(I-760)$ & $21(6-300)$ & $2 I(I-740)$ & ns \\
\hline \multicolumn{5}{|l|}{ Symptoms and signs } \\
\hline Fever $\left(\geq 38^{\circ} \mathrm{C}\right)$ & 370 & 37 & 333 & 0.002 \\
\hline "Common cold" & 95 & 6 & 89 & ns \\
\hline Cough & 226 & 26 & 200 & 0.0009 \\
\hline Malaise & 393 & 21 & 372 & ns \\
\hline \multicolumn{5}{|l|}{ Laboratory findings } \\
\hline ESR (mm/hour) & $13(I-137)$ & 49 & 12 & $<0.0001$ \\
\hline CRP (mg/L) & $17(0-605)$ & 150 & 15 & $<0.0001$ \\
\hline WBC count $\left(\times 10^{9} / L\right)$ & $6.9(0.5-26.7)$ & 10.0 & 6.7 & $<0.0001$ \\
\hline
\end{tabular}

Note: Data are presented as median (range) or as a proportion (ie, $\mathrm{n}[\%]$ ).

Abbreviations: ns, not significant; ESR, erythrocyte sedimentation rate; CRP, C-reactive protein; WBC, white blood cell.

show pulmonary infiltrates than in the general, unselected cohort.

In clinical practice, for patients who had not been selected for chest radiography based on clinical information only, chest radiography may be ordered for those with a high index of suspicion based on clinical signs and symptoms and newly available variables (ie, CRP, ESR, and WBC count). In order to find the optimal selection criteria with high sensitivity and specificity, a decision tree was built using CRT analysis.

Table 2 Logistic regression

\begin{tabular}{lll}
\hline & $\begin{array}{l}\text { Univariate } \\
\text { analysis }\end{array}$ & $\begin{array}{l}\text { Multivariate analysis } \\
\text { OR }(95 \% \mathrm{Cl}, \mathrm{P} \text {-value })\end{array}$ \\
\hline $\begin{array}{l}\text { Symptoms and signs } \\
\text { Fever }\left(\geq 38^{\circ} \mathrm{C}\right)\end{array}$ & $P=0.003$ & $P=0.560$ \\
"Common cold" & $P=0.760$ & $P=0.963$ \\
Cough & $P=0.002$ & $2.80(\mathrm{I} .46-5.38, P=0.002)$ \\
Malaise & $P=0.056$ & $0.40(0.20-0.78, P=0.007)$ \\
Laboratory findings & & \\
ESR $(\mathrm{mm} /$ hour $)$ & $P<0.00 \mathrm{I}$ & $P=0.070$ \\
CRP $(\mathrm{mg} / \mathrm{L})$ & $P<0.00 \mathrm{I}$ & $\mathrm{I} . \mathrm{I} 3(\mathrm{I} .09-\mathrm{I} . \mathrm{I7}, \mathrm{P}<0.00 \mathrm{I})$ \\
WBC count $\left(\times \mathrm{I} 0^{\circ} / \mathrm{L}\right)$ & $P<0.00 \mathrm{I}$ & $\mathrm{I} .08(\mathrm{I} .05-\mathrm{I} . \mathrm{I7}, \mathrm{P}=0.038)$ \\
\hline
\end{tabular}

Notes: All patients $(n=750)$ and the following parameters were entered into a univariate logistic regression, followed by forward stepwise multivariate logistic regression. In multivariate analysis, cough, CRP, and WBC count values predicted the presence of a pulmonary infiltrate, while malaise was negatively correlated with chest radiography findings.

Abbreviations: $\mathrm{OR}$, odds ratio; $\mathrm{Cl}$, confidence interval; $\mathrm{ESR}$, erythrocyte sedimentation rate; CRP, C-reactive protein; WBC white blood cell.
The presence of both cough and fever or absence of either symptom was forced as a first selection variable, simulating the decision previously made purely on clinical grounds. The results are presented in Figure 2. It was found that the previously defined group presenting with both cough and fever could not be further homogenized using any of the evaluated variables. Using CRP with a cut-off value of $23 \mathrm{mg} / \mathrm{L}$, the remaining cohort of 637 patients could be divided into a segment of 271 patients, 27 (10\%) of whom had pulmonary infiltrates, and a lower-risk segment with seven pulmonary infiltrates in 366 patients (1.9\%). These segments could be further stratified into lower or higher risk groups using WBC count and (lower) CRP values.

\section{Discussion}

Respiratory tract infections are among the most frequent illnesses encountered in ill returned travelers, with approximately one-third of those involving the lower respiratory tract. ${ }^{7}$ In ill returned travelers, diagnostic decisions differ greatly from those made in patients from the general population presenting with similar signs and symptoms, and may include routine use of chest radiography. This retrospective cohort study, covering a 3-year observation period, showed that one in 14 of 750 ill returned travelers had evidence of a pulmonary infiltrate on plain chest radiography. 


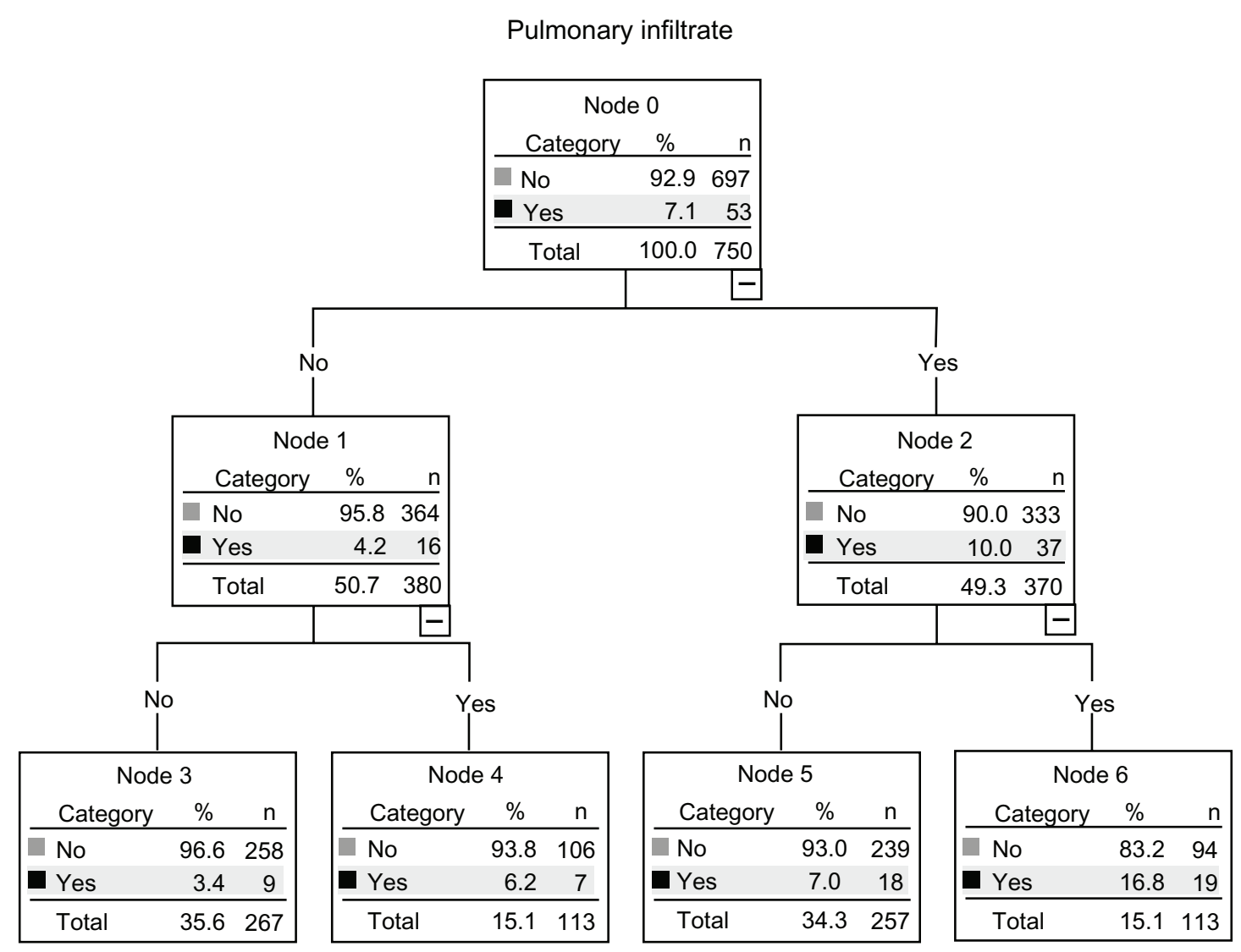

Figure I Recursive partitioning analysis was carried out using the classification and regression tree routine.

Notes: Recursive partitioning analysis was carried out using the classification and regression tree routine, a tree-branching algorithm that recursively seeks to homogenize subsets of the population based on the most predictive variables and their optimal cut-off values. The first analysis was carried out using clinical variables that were available at an early moment. Selection based on the presence of both fever and cough yielded a high-risk terminal node (6) where I9 of II 3 patients (I6.8\%) showed a pulmonary infiltrate, while patients determined to be in the remaining terminal nodes had a significantly lower risk. Nodes represent subgroups identified on subsequent algorithm iterations.

Unsurprisingly, such radiographic findings were seen vastly more frequently in patients presenting with fever, cough, or elevated inflammation parameters.

The results of this study dispute the utility of routine chest radiography in the diagnostic work-up of ill returned travelers independently of their presentation. In multivariate analysis the presence of fever and elevated ESR values correlated with chest radiography abnormalities, this correlation was found not to be significant in multivariate logistic regression, most likely due to the stronger predictive value of CRP. Surprisingly, symptoms of malaise were negatively correlated with the presence of a pulmonary infiltrate, a phenomenon for which we have no sound explanation.

Using recursive partitioning analysis, we built a decision tree and were able to identify a segment of the cohort that would optimally benefit from chest radiography based on immediately available clinical parameters. To better approximate clinical practice where a clinician may want to order chest radiography for ill returned travelers who have an increased index of suspicion based not only on their clinical parameters but on newly available laboratory test results, we repeated the above analysis with all available variables, with the presence of both cough and fever as a first forced selection criterion. The resulting tree classified 366 patients as negative based on the absence of either fever or cough and a CRP value under $23 \mathrm{mg} / \mathrm{L}$. With seven (1.9\%) false negatives in this group, and given the uncertainties surrounding the clinical relevance of pulmonary infiltrates in patients with CRP values under $23 \mathrm{mg} / \mathrm{L}$, it seems unnecessary to order chest radiography in this cohort, avoiding unnecessary radiation exposure in a large number of patients. Conversely, cohorts presenting with cough and fever, or with CRP values in excess of $23 \mathrm{mg} / \mathrm{L}$ represented patients with a high risk of exhibiting abnormalities on chest radiography. Diagnostic accuracy in the latter group could be further enhanced by using a cut-off value of $6.5 \cdot 10^{9} / \mathrm{L}$ for WBC count as a selection criterion. It may be possible to increase diagnostic accuracy using information gained from physical examination not present in this study.

We advocate a more judicious use of chest radiography in the diagnostic work-up of ill returned travelers, which will 


\section{Pulmonary infiltrate}

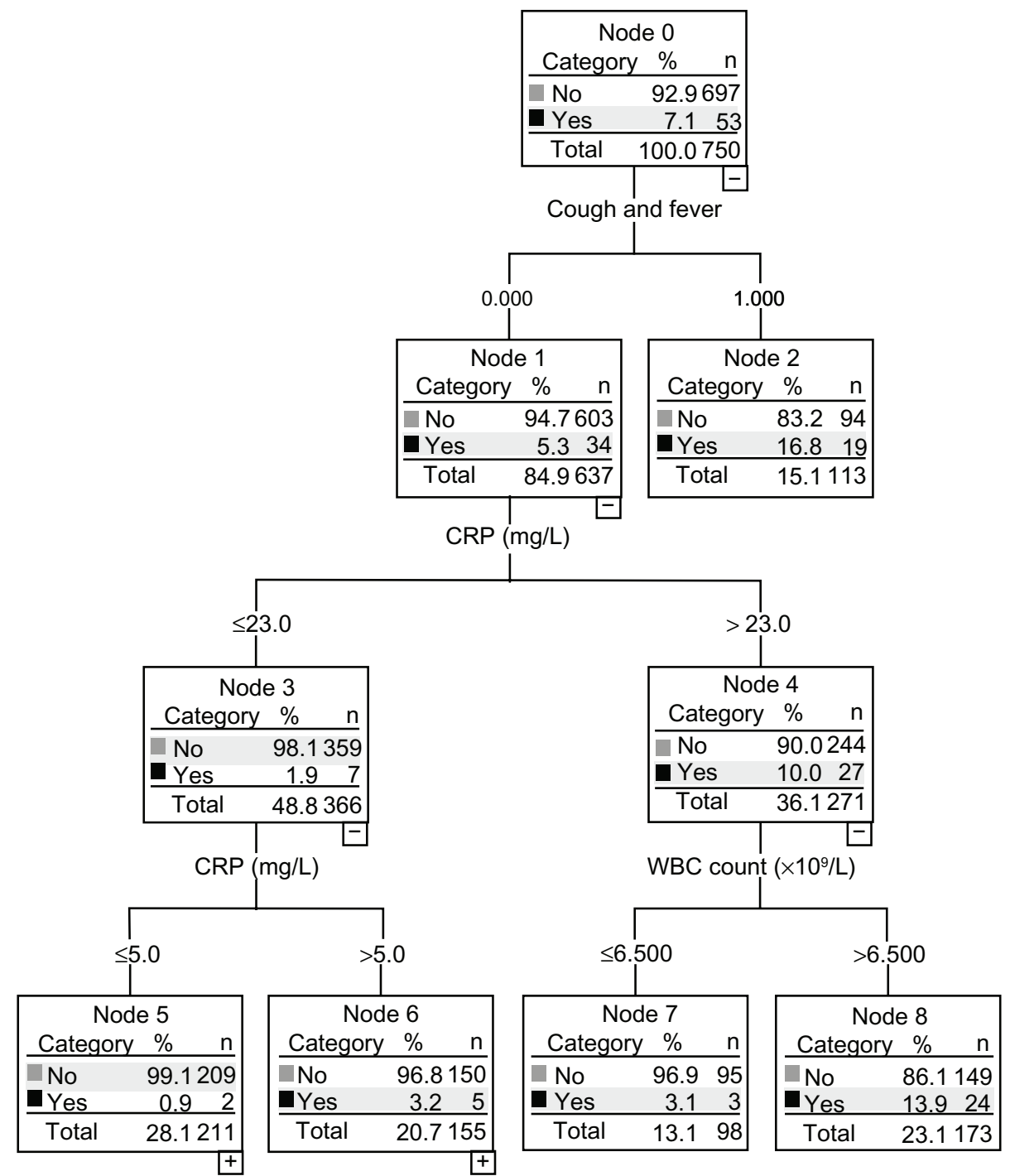

Figure 2 CRT analysis of all available parameters.

Notes: To resemble clinical practice where initial, clinical information-based diagnostic decisions may be revised when additional information becomes available (such as inflammation parameter levels), CRT analysis was carried out with all available parameters, using the presence or absence of both cough and fever as a first forced variable. It is shown that the earlier defined high-risk group could not be further homogenized, while for the lower-risk group, CRP values in excess of $23 \mathrm{mg} / \mathrm{L}$ predicted a high risk of pulmonary infiltrate. The risk could be further specified using (lower) cut-off values for CRP and WBC count. Nodes represent subgroups identified on subsequent algorithm iterations. Abbreviations: CRT, classification and regression tree; CRP, C-reactive protein; WBC, white blood cell.

not only prevent unnecessary exposure to potentially harmful radiation, but it will also considerably reduce costs.

To our knowledge, this study is the first of its kind first to evaluate the value of routine chest radiography in the diagnostic work-up of ill returned travelers. In conclusion, the results of this retrospective cohort study indicate that chest radiography should only be used in the diagnostic work-up of a carefully selected subset of all ill returned travelers seeking medical advice.

\section{Disclosure}

The authors report no conflicts of interest in this work.

\section{References}

1. Hill DR. Health problems in a large cohort of Americans traveling to developing countries. J Travel Med. 2000;7(5):259-266.

2. Bruni M, Steffen R. Impact of travel-related health impairments. JTravel Med. 1997;4(2):61-64.

3. Cossar JH, Reid D, Fallon RJ, et al. A cumulative review of studies on travellers, their experience of illness and the implications of these findings. J Infect. 1990;21(1):27-42.

4. Kemmerer TP, Cetron M, Harper L, Kozarsky PE. Health problems of corporate travelers: risk factors and management. J Travel Med. 1998; 5(4):184-187.

5. Scoville SL, Bryan JP, Tribble D, et al. Epidemiology, preventive services, and illnesses of international travelers. Mil Med. 1997;162(3):172-178.

6. Ahlm C, Lundberg S, Fessé K, Wiström J. Health problems and selfmedication among Swedish travellers. Scand J Infect Dis. 1994;26(6): $711-717$. 
7. Ansart S, Perez L, Vergely O, Danis M, Bricaire F, Caumes E. Illnesses in travelers returning from the tropics: a prospective study of 622 patients. J Travel Med. 2005;12(6):312-318.

8. Moolenaar C, van Genderen PJ. Value of routine sinus radiography in the diagnostic work-up of ill returned travelers: critical appraisal in a cohort of 765 travelers. Int J Gen Med. 2011;4:313-316.
9. Breiman L, Friedman JH, Olshen RA, Stone CJ. Classification and Regression Trees. Boca Raton, FL: Chapman and Hall/CRC; 1984.

\section{Publish your work in this journal}

The International Journal of General Medicine is an international, peer-reviewed open-access journal that focuses on general and internal medicine, pathogenesis, epidemiology, diagnosis, monitoring and treatment protocols. The journal is characterized by the rapid reporting of reviews, original research and clinical studies across all disease areas.
A key focus is the elucidation of disease processes and management protocols resulting in improved outcomes for the patient.The manuscript management system is completely online and includes a very quick and fair peer-review system. Visit http://www.dovepress.com/ testimonials.php to read real quotes from published authors.

Submit your manuscript here: http://www.dovepress.com/international-journal-of-general-medicine-journal 